\title{
Highly conductive coatings of carbon black/silica composites obtained by a sol-gel process
}

\author{
E. Enríquez , J.F. Fernández, M.A. de la Rubia
}

\section{Introduction}

Conductive coatings have been widely investigated to achieve new applications as transparent electrodes [1], as enhancement of the corrosion resistance, or as conductive paints for static charge dissipation [2]. Carbon black (CB) is of great interest due to its variety of applications. CB is produced by incomplete combustion of gaseous and liquids hydrocarbons [3], and it typically possesses a wide particle size distribution, from $10 \mathrm{~nm}$ to $100 \mu \mathrm{m}[4,5]$. Its main use is as rubber filler or reinforcement in paints, polymers or gums. It is also used as pigment in polymer materials, to improve physical and mechanical properties of composites (hardness, tear strength, fatigue) and as UV protection material $[5,6]$. The addition of $\mathrm{CB}$ to polymer or epoxy based composites allows obtaining different ranges of resistivity, $10^{-1}-10^{-3} \Omega \mathrm{m}[4,7]$. Conductive composites are used to dissipate static electricity, in electronic devices, as electromagnetic interference shielding, or as electrodes $[8,9]$. The main drawback of $\mathrm{CB}$ is its strong agglomeration state due to its hydrophobicity. The CB dispersion in the composite strongly affects its conduction response that is determined by the percolation limit $[8,10]$. There are several processes to homogeneously disperse CB nanoparticles in an insulating matrix [4,11], as surfactant addition [5,12-14], or high speed disperser equipments (cowles disperser) or attrition milling. A silica matrix is an appropriate environment to carry out a homogenous distribution of $\mathrm{CB}$ particles. Silica inorganic matrix is easily obtained by the sol-gel (SG) process [15]. SG silica matrix is widely used to form glass insulating coatings due to its advantageous properties: chemically inert and physically resistant, tunable porosity and low temperature processing. In addition, the sol-gel method provides coatings with controlled thickness $[16,17]$.

The preparation of dense thin coatings by the sol-gel method, with conductive properties (low resistivity) at the 
nanoscale, is not obvious. The homogeneous incorporation and the chemical and thermal stability of CB in the silica matrix depend on different parameters as coating thickness, particle size, deposition method and thermal treatment. Conductive coatings have been previously used to improve the electrical response of glassy carbon electrodes $[18,19]$, but there is an absence of references related to the obtaining of conductive thin coatings of CB/silica composites by the solgel method. Therefore, the carbon based conductive submicronic coatings present great difficulties to be developed [20].

The aim of this work is to afford a complete experimental study of rheological, structural and thermal behavior of $\mathrm{CB}$ powders to obtain conductive thin films by the sol gel method. An adequate dispersion state of the $C B$ is required to achieve appropriate $C B$ percolation and efficient encapsulation within the silica matrix. Therefore, the vitreous inorganic material contributes to consolidate the CB thin coating with conductive properties, improving its adhesion to the glazed substrate.

\section{Experimental procedure}

\subsection{Materials}

Carbon black (CB) PUREX ${ }^{\circledR}$ HS 55 (powder, Degussa), density $0.335 \mathrm{~g} / \mathrm{cm}^{3}$, having an agglomerate size of $1.4-1.7 \mu \mathrm{m}$ and a high specific surface area, of $40 \mathrm{~m}^{2} / \mathrm{g}$, was used as starting materials. The reagents used to prepare the sol were tetraethyl orthosilicate $99 \%$ (TEOS, Sigma Aldrich) as silica precursor, ethanol absolute $99.9 \%$ (MERCK) as solvent and deionized water and hydrochloric acid $37 \%$ (MERCK) as catalysts. The surfactant used to disperse $\mathrm{CB}$ nanoparticles in water was Triton $\mathrm{X}-100(\mathrm{~T})$ (Sigma-Aldrich) which is a non-ionic surfactant with a hydrophilic polyethylene oxide group, $-\left(\mathrm{OCH}_{2} \mathrm{CH}_{2}\right)_{n} \mathrm{OH}$, a phenyl group and a hydrocarbon hydrophobic group $\left(\mathrm{CH}_{3}-\right.$ $\left.\mathrm{C}_{3} \mathrm{H}_{6}-\mathrm{CH}_{2}-\mathrm{C}_{3} \mathrm{H}_{6}\right)\left(\mathrm{C}_{8} \mathrm{H}_{17}\right)$. Triton $\mathrm{X}-100$ has an "average of $n=9.5$ " ethylene oxide units per molecule.

\subsection{Sample preparation}

Samples consisted on silica/CB composites coatings deposited on glaze porcelain tiles substrates using the spray method and sintered in air atmosphere. The substrates were provided by the company Roca Sanitarios S.A and they are composed of a part of sanitaryware porcelain which composition is widely known, and a glazed coating having $\sim 400 \mu \mathrm{m}$ in thickness, based mainly on $\mathrm{SiO}_{2}, \mathrm{ZrO}_{2}, \mathrm{Al}_{2} \mathrm{O}_{3}, \mathrm{CaO}$ and low content of $\mathrm{K}_{2} \mathrm{O}$ and $\mathrm{Na}_{2} \mathrm{O}$ [21]. This glaze coating has closed porosity and a thermal expansion coefficient of $6.1 \times 10^{-6}{ }^{\circ} \mathrm{C}$ ${ }^{-1}\left(300-500^{\circ} \mathrm{C}\right)$. Both glaze coating and sol-gel coating are silica-based, favoring their physical and chemical compatibility.

Prior to coating deposition, the substrates were cleaned with soapy water and ethanol, and further drying at room temperature. The sol was prepared with the following reagents proportion: $1 \mathrm{TEOS}: 8 \mathrm{EtOH}: 3 \mathrm{H}_{2} \mathrm{O}: 0.01 \mathrm{HCl}: \mathrm{xCB}$, where $x=0,10,20,40,50,60$ and 70 wt. $\%$ of CB. In order to obtain an adequated dispersion of $C B$ nanoparticles to achieve highly homogenous coatings and therefore, better electrical response, it was required to add a surfactant [22,23], Triton $\mathrm{X}-100$. Hence, CB nanoparticles were previously dispersed in water (20 wt.\% solid content) to study the appropriate amount of Triton X-100 from 0-10 wt.\%, in a high shear disperser (SL-1 ADF Disperser Lleal) that works at $50 \mathrm{~Hz}, 220 \mathrm{~V}$ and 5,5A. The dried dispersed $C B$ powders were added to the solvent and homogenized using a high shear disperser during $10 \mathrm{~min}$. Then, silica precursor, water and catalyst were added to the solvent to form the sol solution. The sol was stirred at room temperature during $1 \mathrm{~h}$, time in which the heat generated in the solution by the hydrolysis reaction dissipates. Coatings were deposited on tiles by spray. The samples were thermally treated in air at $300^{\circ} \mathrm{C}$ during $5 \mathrm{~h}$ or at 400 and $500^{\circ} \mathrm{C}$ during $1 \mathrm{~h}$.

\subsection{Characterization}

Viscosity measurements of dispersed CB powders in water were carried out by means of a Haake Viscosimeter System Rotovisco RV 2076 with Controller RC 20 and M5 head that uses computer-controlled coaxial cylinder ZA30. The temperature of the sample was controlled with a Haake F3 thermostat at $25^{\circ} \mathrm{C}$. Differential Thermal and Thermogravimetric Analysis (DTA-TG) of CB raw powders, dried silica and $\mathrm{CB} /$ silica powders obtained by sol-gel (SG), were performed using a Netzsch STA $409 / \mathrm{C}$ equipment, in the range of $30-1000^{\circ} \mathrm{C}$ with a heating rate of $10 \% \mathrm{~min}$ in air atmosphere. Fourier Transform Infrared spectroscopy (FT-IR) of samples was carried out by a FT-IR spectrometer, Perkin Elmer, Spectrum 100. Microstructural characterization was studied by means of Field Emission Scanning Electron Microscopy (FE-SEM) using a Hitachi TM1000. Microstructure was attempted by Confocal Raman spectroscopy using a Witec Micro-Raman Confocal coupled with an AFM (ALPHA 300RA) with a Nd:YAG laser excitation at $532 \mathrm{~nm}$ and an oil immersion $100 \times$ objective (NA $=0.9$ ). The laser power used for the measurements was as low as $0.7 \mathrm{~mW}$ in order to minimize as much as possible the heating effect over the coating due the high absorption of CB powders. The optical resolution of the confocal microscope was limited to $200 \mathrm{~nm}$ in lateral direction and to $500 \mathrm{~nm}$ in vertical direction. Raman spectral resolution of the system is down to $0.02 \mathrm{~cm}^{-1}$. The samples were mounted in a piezo-driven scan platform having a positioning accuracy of $4 \mathrm{~nm}$ in lateral and $0.5 \mathrm{~nm}$ in vertical. The piezoelectric scanning table allows three-dimensional displacements in steps of $3 \mathrm{~nm}$, giving a very high spatial resolution for both the AFM and the Confocal Raman microscopy. The microscope base was also equipped with an active vibration isolation system, active in the range $0.7-1000 \mathrm{~Hz}$. The acquired spectrum were processed and analyzed using the WITec Project 2.02 program, which allows a specific, sensitive, immune to interferences and non-intrusive analysis of crystals and provides a method for characterizing chemical properties of heterogeneous samples, with great resolution and rapid data collection. High resolution images of Raman depth profile mapping were carried out to determine the coating thickness. In addition, the coating thickness was also determined by Field Emission Scanning Electron Microscopy in the cross section of the sample. Porosimetry of the hybrid sol gel dried powders were obtained by using an automatic PoreMaster ${ }^{(i)}$ mercury intrusion porosimeter (Quantachrome instruments) for high-resolution pore size measurements in the range from $7 \mathrm{~nm}$ to $250 \mu \mathrm{m}$ pore 
diameter. The resistivity measurements of submicronic coatings were carried out with a multimeter Keithley 2410-1100 V, in voltage and current ranges of $0-100 \mathrm{~V}$ and $0-21 \mathrm{~mA}$, respectively. The electrodes used were conductive copper tapes, AT526 35 Micron Copper Foil Shielding tape from Advance Tapes, with conductive acrylic adhesive and good high and low temperature resistance.

\section{Results and discussion}

\subsection{Rheological properties}

Rheological behavior of suspensions with different Triton $\mathrm{X}$ $100, \mathrm{~T}$, content is shown in Fig. 1. Selected suspensions correspond to the highest and lowest viscosity samples (2.75 and $5 \mathrm{wt}$ \% T, respectively), were compared with a CB suspension without surfactant (Fig. 1a). The rest of suspensions have similar or intermediate behavior to these ones, so, they are not represented for the sake of clarity.

At shear speeds below $60 \mathrm{~s}^{-1} \mathrm{CB}$ suspensions with $<5 \mathrm{wt} \%$ of surfactant has an incipient gel structure formation due to the interaction between $\mathrm{CB}$ agglomerates. The inset of Fig. 1a, wich represents viscosity versus shear speed, shows the typical curve of a shear thinning fluid or pseudoplastic behavior. At this step we assumed that CB suspension consisted of small size CB agglomerates because a primary particle is almost impossible to be attained in water $[5,6,11,24,25]$. Moreover, the structure of Triton X-100 (Fig. 2a) can interact with CB by means of two possible processes [26]: (a) the hydrophobic $(\mathrm{C}-\mathrm{H})$ and/or phenyl groups of surfactant interact with the $\mathrm{C}-\mathrm{C}$ and $\mathrm{C}=\mathrm{C}$ bonds of the $\mathrm{CB}$ particles by Van der Waals interactions; (b) oxyethylene groups of surfactant interact with $\mathrm{CB}$ by means of hydrogen bonds. When the agglomerates are partially coated by the surfactant (Fig. 2b), its functional groups allow to form polymeric type structures. Therefore, higher shear stress is required to break down this polymeric type structure resulting in a high viscosity suspension at low shear speed (Fig. 1a). When increasing the surfactant content, CB agglomerates are fully coated and therefore the steric effect avoids inter-agglomerate interactions (Fig. 2c), the suspension behaves almost as a pure Newtonian fluid and as a consequence viscosity is reduced [27]. High surfactant content is therefore favorable to increase the carbon content in the suspensions.
Fig. 1b shows the viscosity of CB suspensions for different surfactant contents at selected shear speeds. It can be observed that, independently of the shear speed, the viscosity increases from $1 \mathrm{wt} \%$ of Triton X-100 and reaches a maximum for $\sim 2.75 \mathrm{wt}$. \%. Above this surfactant content, the viscosity begins to decrease until it reaches a minimum for $\sim 5 \mathrm{wt} . \%$. These differences are more pronounced for lower shear speed.

\subsection{Thermal and infrared analysis}

Fig. 3 shows the DTA-TG of pure CB (CB powder), sol gel of silica $(\mathrm{SG} \mathrm{SiO})_{2}$ ) and sol gel of $\mathrm{CB} /$ silica having $5 \mathrm{wt}$.\% of Triton $\mathrm{X}-100$ (SG CB-SiO $\mathrm{S}_{2}-5 \% \mathrm{~T}$ ). The SG CB-SiO $2-5 \% \mathrm{~T}$ sample has $50 \mathrm{wt}$. $\%$ of $\mathrm{CB}$. The $\mathrm{CB}$ powders degradation onset due to oxidation takes place at $\sim 430^{\circ} \mathrm{C}$ and this process is completed at $647^{\circ} \mathrm{C}$ (Fig. 3b). The $\mathrm{SG} \mathrm{SiO}_{2}$ begins to lose mass gradually at $\sim 50^{\circ} \mathrm{C}$ which corresponds both to the dehydration and alcohol evaporation. The onset of the silica polycondensation ( $\mathrm{Si}-\mathrm{O}-\mathrm{Si}$ ) $[28,29]$, takes place at $\sim 320^{\circ} \mathrm{C}$ and shows a weak exothermic peak at $\sim 370^{\circ} \mathrm{C}$. The CB degradation onset takes place at $>430^{\circ} \mathrm{C}$, being complete at $621^{\circ} \mathrm{C}$. According to that, the onset and complete degradation temperatures of $\mathrm{CB}$ are shifted to higher temperatures ( $\sim 60$ and $40^{\circ} \mathrm{C}$, respectively) when $\mathrm{CB}$ is introduced into the SG based silica matrix. CB nanoparticles were encapsulated and protected against oxidation by the inorganic silica matrix. Despite the silica matrix encapsulation of the $\mathrm{CB}$, the appearance of the Si-C interaction between CB powder and the silica matrix is not evidenced from the DTATG. In addition, the SG $\mathrm{CB}-\mathrm{SiO}_{2}-5 \% \mathrm{~T}$ composition lost $\sim 50$ wt. $\%$ at temperatures $>650^{\circ} \mathrm{C}$ consequence of the complete oxidation of CB powder. The composite sample without surfactant shows very similar behavior than the one with surfactant so the DTA-TG curves are omitted.

To clarify the CB encapsulation mechanisms of the SG silica, FTIR-ATR analysis of samples with different thermal treatments were carried out. Fig. 4 a shows the FTIR-ATR spectra of a SG $\mathrm{SiO}_{2}$ coating sintered at $500^{\circ} \mathrm{C} / 1 \mathrm{~h}$ and SG CB-SiO ${ }_{2}$ coatings sintered at $300^{\circ} \mathrm{C} / 5 \mathrm{~h}$ and $500^{\circ} \mathrm{C} / 1 \mathrm{~h}$. The inset shows the same spectra in an extended wavenumber range. The different absorption peaks observed are associated with vibration modes of $\mathrm{Si}-\mathrm{O}-\mathrm{Si}$ bonds: stretching $\mathrm{LO}$ mode, $1045 \mathrm{~cm}^{-1}$, TO mode, $1155 \mathrm{~cm}^{-1}$, and bending mode, $795 \mathrm{~cm}$ ${ }^{-1}$, in agreement with previous data $[30,31]$. The FTIR-ATR spectra confirm that the weak exothermic peak found at
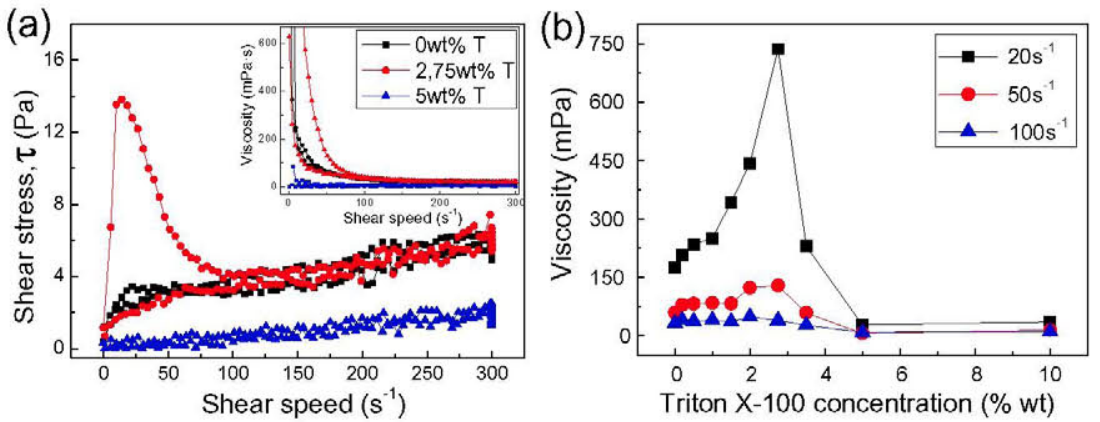

Fig. 1 - Rheological properties for CB suspensions with different concentrations of surfactant: (a) shear speed versus shear stress for selected suspensions. The inset shows viscosity versus shear stress of the same samples; (b) viscosity as a function of surfactant concentration for different shear speeds. 


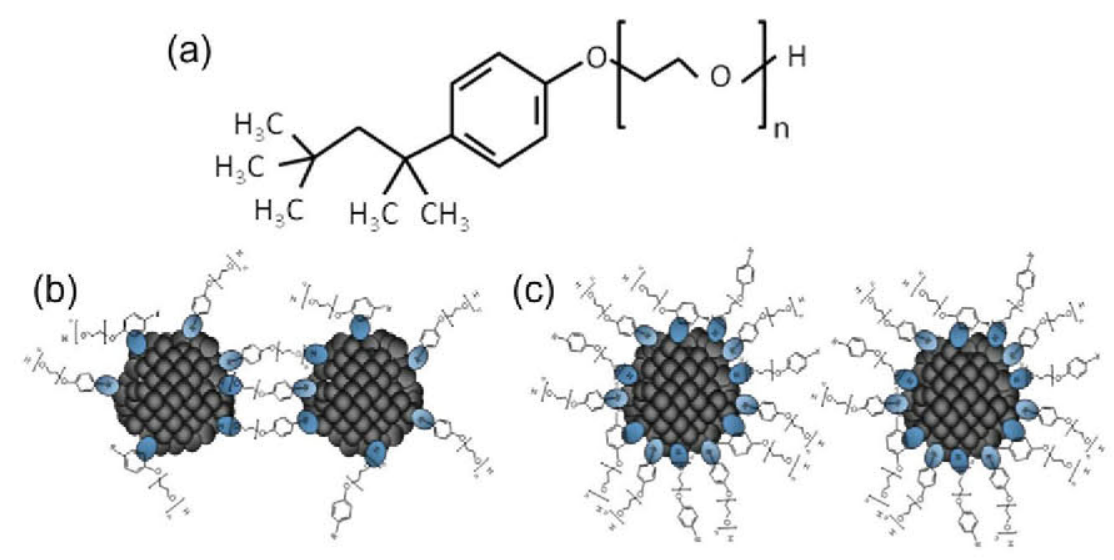

Fig. 2 - (a) Triton X-100 molecule; (b) and (c) show schematically the interactions between Triton X-100 and CB agglomerates, where the blue circles represent an interaction between one of the three chemical groups of the Triton $\mathrm{X}-100$ and the $\mathrm{CB}$, producing: (b) partially-coated CB agglomerates that show attracting behavior; (c) fully coated agglomerates with steric repulsion behavior (For interpretation of the references to color in this figure legend, the reader is referred to the web version of this article).
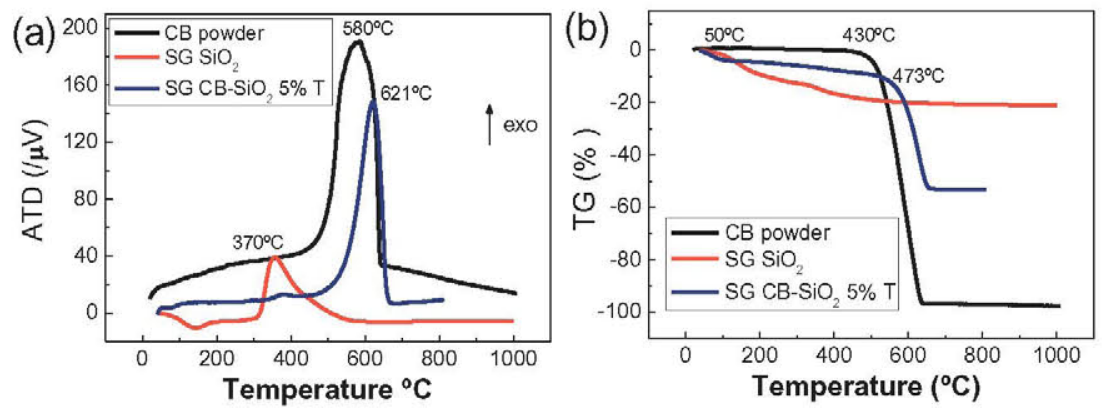

Fig. 3 - DTA-TG analysis of dried powders: $\mathrm{CB}$, silica sol gel ( $\left.\mathrm{SG} \mathrm{SiO}_{2}\right)$ and sol gel composite containing 50 wt.\% of $\mathrm{CB}$ with 5 wt. $\%$ of surfactant (SG CB-SiO 2 $5 \%$ T), (a) DTA; (b) TG.
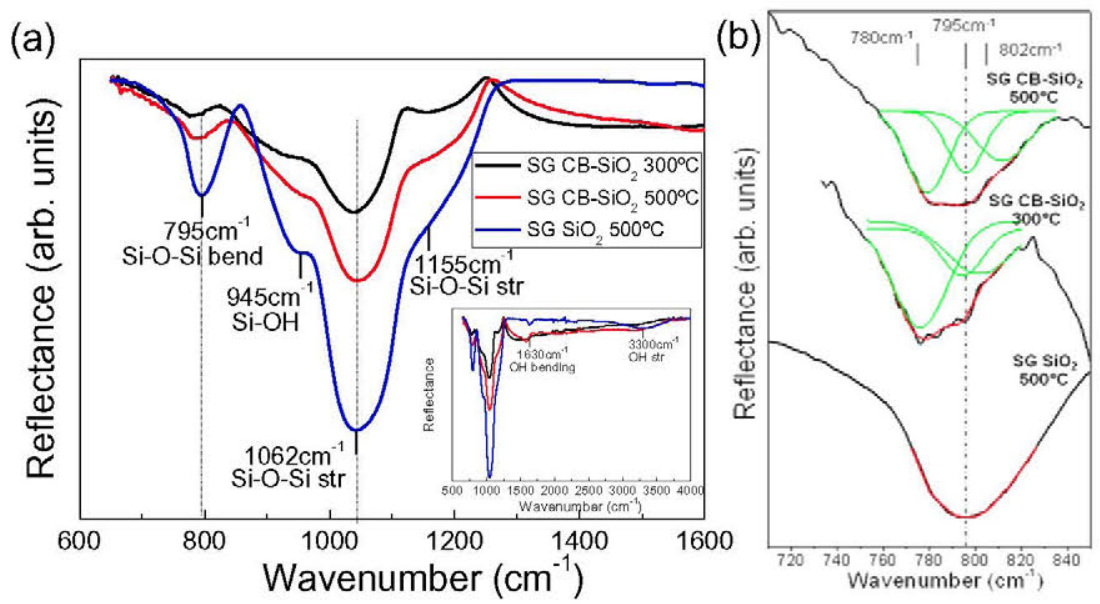

Fig. 4-FTIR-ATR spectra of (a) SG $\mathrm{SiO}_{2}$ sample sintered at $500^{\circ} \mathrm{C} / 1 \mathrm{~h}$ and SG CB-SiO${ }_{2}$ samples treated at $300{ }^{\circ} \mathrm{C} / 5 \mathrm{~h}$ and $500{ }^{\circ} \mathrm{C} /$ $1 \mathrm{~h}$, and an inset showing the spectra in an extended wavenumber range; (b) the deconvolution of the peak around $795 \mathrm{~cm}^{-1}$.

$370^{\circ} \mathrm{C}$ in the DTA curve (Fig. $3 a$ ) corresponds to the $\mathrm{Si}-\mathrm{O}-\mathrm{Si}$ polycondensation process. The densification degree of the samples can be analyzed in these spectra by comparing both the band shift of Si-O-Si bonds and the intensity of the peaks at different temperatures. The $\mathrm{Si}-\mathrm{O}-\mathrm{Si}$ peaks shift to higher wavenumbers when the sintering temperature increases, which indicates higher bond energies, that is, greater densification. In addition, it is clearly observed an intensity increase of the main peak, ca. $1045 \mathrm{~cm}^{-1}$, with the temperature treatment. This increase is greater for the silica sample be- 
cause the composition is purely $\mathrm{SiO}_{2}$. Therefore, SG CB-SiO coatings require too high sintering temperatures to improve the densification. In Fig. $4 a$ it can also be observed a peak, ca. $945 \mathrm{~cm}^{-1}$, attributed to the stretching mode of $\mathrm{Si}-\mathrm{OH}$. Moreover, organic residues due to an incomplete hydrolysis of TEOS at the followed thermal treatment have been not found in the silica coating, as evidenced by the absence of defined peaks corresponding to $\mathrm{C}-\mathrm{H}$ vibrations in -OEt groups, located at ca. $3000 \mathrm{~cm}^{-1}$ and ca. $1300-1500 \mathrm{~cm}^{-1}$, inset of Fig. $4 \mathrm{a}$, in agreement with previous results [30]. The presence of a broad band ca. $1350 \mathrm{~cm}^{-1}$ can be attributed to these organic residuals retained by the $C B$ powders, but the absence of a band at ca. $3000 \mathrm{~cm}^{-1}$ indicates low or negligible presence compared to other compounds.

According to the literature the $\mathrm{Si}-\mathrm{O}-\mathrm{C}$ vibration modes appear at $780 \mathrm{~cm}^{-1}$ and $1220 \mathrm{~cm}^{-1}$, and the $\mathrm{Si}-\mathrm{C}$ stretching mode at $802 \mathrm{~cm}^{-1}$ [32-38]. Therefore, a peak deconvolution is attempted to resolve the broad peak around $780-800 \mathrm{~cm}^{-1}$ (Fig. 4b). The $\mathrm{SG} \mathrm{SiO}_{2}$ coating band could be deconvoluted in a single Gaussian that strictly corresponds to the $\mathrm{Si}-\mathrm{O}-\mathrm{Si}$ bonds. In the other samples three different peaks were resolved: (a) $780 \mathrm{~cm}^{-1}$, attributed to C-O bonds; (b) $795 \mathrm{~cm}^{-1}$, corresponding to $\mathrm{Si}-\mathrm{O}-\mathrm{Si}$ bonds which shifted to higher wavenumber with increasing temperature; (c) $802 \mathrm{~cm}^{-1}$ associated to the stretching mode of $\mathrm{Si}-\mathrm{C}$. The $\mathrm{Si}-\mathrm{O}-\mathrm{Si}$ bands shift to higher wavenumbers at higher sintering temperatures indicating that the densification process occurs. The Si-C band was more clearly resolved at higher thermal treatment temperatures, $>300^{\circ} \mathrm{C}$. In addition a broad peak that could correspond to the asymmetric stretching modes of $\mathrm{Si}-\mathrm{O}-\mathrm{C}$, ca. $1100-1200 \mathrm{~cm}^{-1}$ can be observed (Fig. 4a). As expected, FTIRATR results corroborate the presence of $\mathrm{Si}-\mathrm{O}-\mathrm{Si}$ bonds. Therefore, FTIR-ATR results suggest the appearance of CB-Silica interactions by means of $\mathrm{Si}-\mathrm{C}$ and $\mathrm{Si}-\mathrm{O}-\mathrm{C}$ bonds.

In summary, according to DTA-TG and FTIR analysis, the appropriate range for the thermal treatments of the SG CB-silica composites should be $370^{\circ} \mathrm{C}<\mathrm{T}<620^{\circ} \mathrm{C}$, and so, the thermal treatments at $300-600^{\circ} \mathrm{C}$ were pursuit. At temperatures $<370^{\circ} \mathrm{C}$, to improve the densification of the silica matrix, the sintering temperature was extended during $5 \mathrm{~h}, 300^{\circ} \mathrm{C} / 5 \mathrm{~h}$. At higher temperatures, the thermal treatments were carried out during $1 \mathrm{~h}, 400^{\circ} \mathrm{C} / 1 \mathrm{~h}$ and $500^{\circ} \mathrm{C} / 1 \mathrm{~h}$. Heating and cooling rates of $1^{\circ} \mathrm{C} / \mathrm{min}$ and $3^{\circ} \mathrm{C} / \mathrm{min}$ respectively, were used in all thermal treatments.

\subsection{Carbon black concentration}

Fig. 5a presents the dependence of electrical properties with the $\mathrm{CB}$ concentration in composite coatings prepared by the sol-gel process. The samples were densified at $300^{\circ} \mathrm{C} / 5 \mathrm{~h}$. The thickness of these coatings is $\sim 500 \mathrm{~nm}$ as observed from FE-SEM transversal image in the SG $50 \mathrm{wt} . \% \mathrm{CB}-\mathrm{SiO}_{2}$ fractured sample (Fig. 6). A good adhesion interface between the SG CB$\mathrm{SiO}_{2}$ coating and the surface of the glazed tile appears. The thickness of the other analyzed samples is similar to this one.

Resistance was determined using a digital multimeter at room temperature, and resistivity, $\rho$, was calculated by means of Eq. (1).

$\mathrm{R}=\rho \mathrm{L} / \mathrm{A}$

where $L$ is the sample length, $A$ is the cross-sectional area, $\rho$ is the resistivity, and $R$ the resistance. Then, conductivity can be calculated since it is the reverse of resistivity $(\sigma=1 / \rho)$. In Fig. $5 \mathrm{a}$ it is easy to observe that, as expected, the concentration of $\mathrm{CB}$ powders and resistivity are inversely related. At low $\mathrm{CB}$ concentrations ( $\leqslant 10 \mathrm{wt} . \%$ ) resistivity is quite high, and significantly decreases above $40 \mathrm{wt} \%$. Between 10 and 20 wt. \% of CB a sharp reduction of the resistivity occurs, however, the resistivity is still high. At $50 \mathrm{wt}$ \% of CB the resistivity reaches the lowest value, since the dispersed conductive particles/agglomerates interconnect each other to give rise to a conductive path, achievement the percolation limit. This

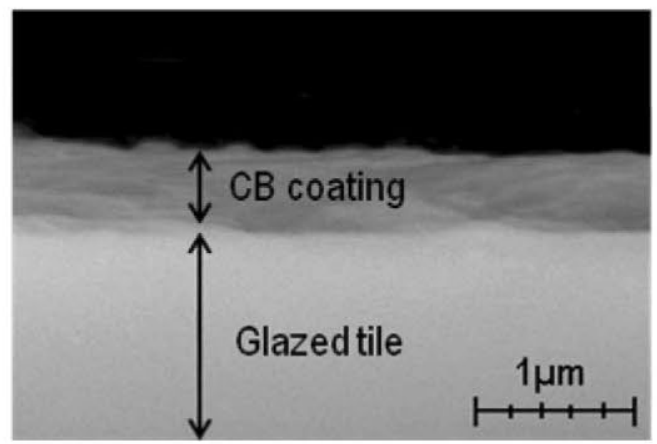

Fig. 6 - SEM image of the transversal section of a silica coating containing $50 \mathrm{wt} . \%$ CB sintered at $300 \mathrm{C} / 5 \mathrm{~h}$.
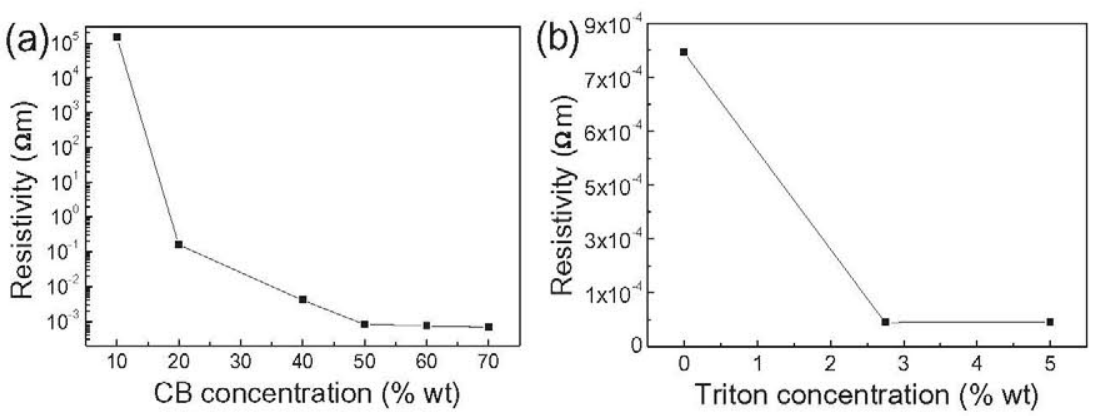

Fig. 5 - Dependence of DC resistivities of samples prepared with different (a) CB and (b) surfactant concentrations, thermally treated at $300^{\circ} \mathrm{C} / 5 \mathrm{~h}$. 

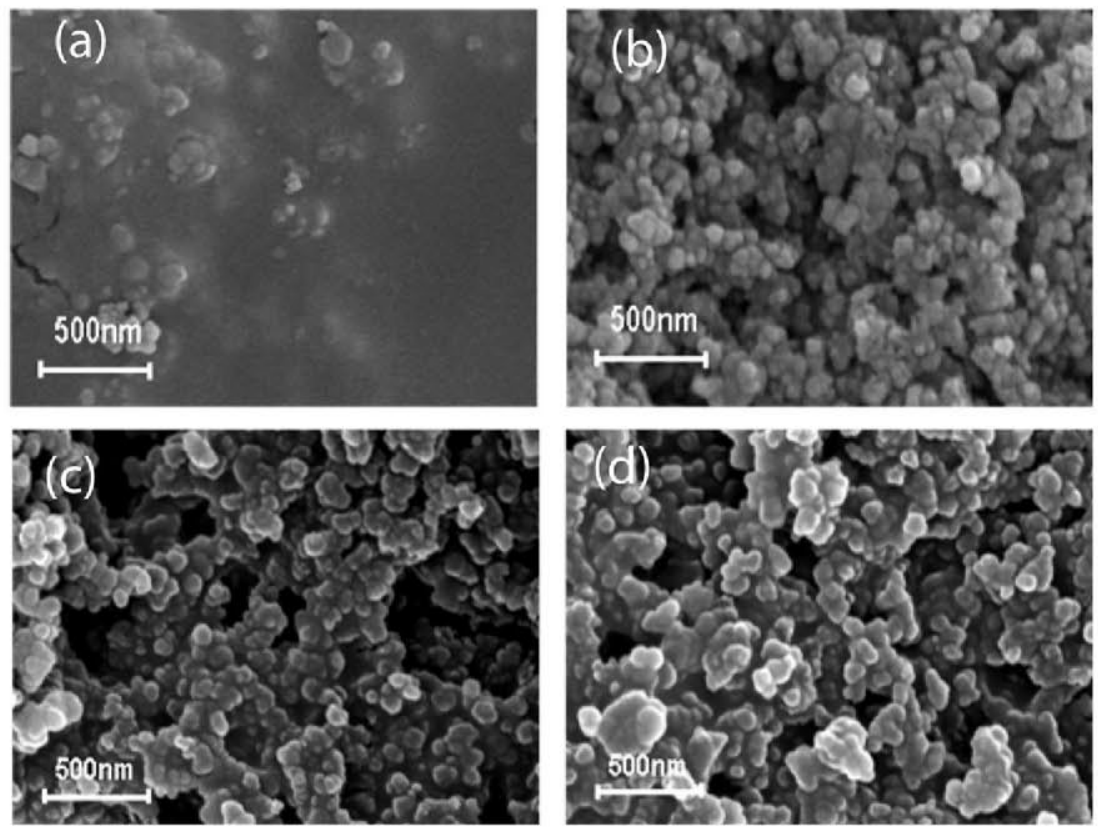

Fig. 7 - FESEM micrographs of SG CB-SiO 2 coatings with (a) 10 wt.\% CB, (b) 50 wt.\% CB without surfactant, (c) 50 wt. $\%$ CB with 2.75 wt. $\%$ Triton X-100, (d) 5 wt. $\%$ CB with Triton X-100. All coatings sintered in air at $300{ }^{\circ} \mathrm{C} / 5 \mathrm{~h}$.

interconnection can be produced by nanoparticle contacts or by tunnel effect [4]. Higher CB contents, over the percolation limit, failed to further decrease the resistivity values. It is worth to note that resistivity measurements were attempted in large coating areas, typically $3 \times 2 \mathrm{~cm}^{2}$. Therefore, the resistivity measurements are a macroscopic evidence of the functional performance of the coating. In addition, high reproducibility of SG based coatings was stated, based on resistivity values consistence in different samples. The range of $\mathrm{CB}$ concentration where the percolation limit takes place is the same for samples sintered at $400^{\circ} \mathrm{C} / 1 \mathrm{~h}$ and $500^{\circ} \mathrm{C} / 1 \mathrm{~h}$, so it can be concluded that the percolation limit is independent of the followed thermal treatment, as expected.

The above results are supported by the micrographs presented in Fig. $7 \mathrm{a}$ and $\mathrm{b}$ that show the FE-SEM micrographs

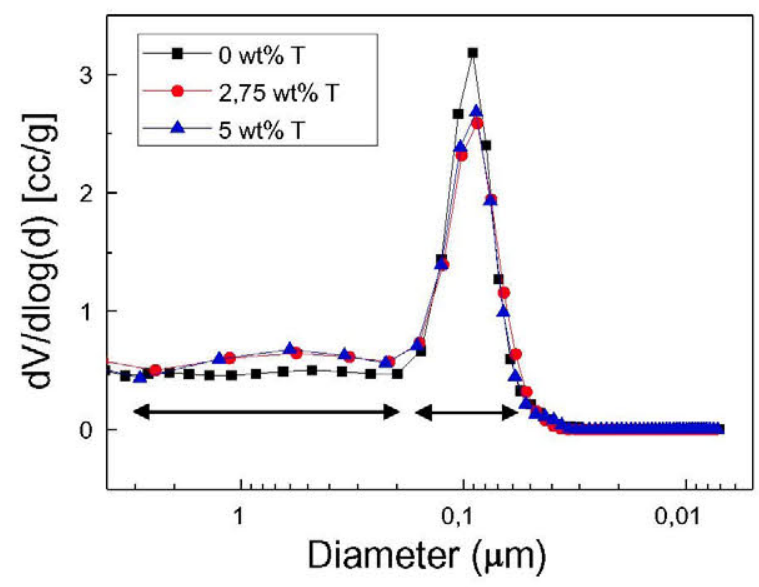

Fig. 8- Mercury intrusion porosimetry of room temperature dried powder of SG CB-SiO 2 with 50 wt.\% CB and different Triton X-100 contents. of coatings with 10 and $50 \mathrm{wt} . \%$ of CB respectively, sintered at $300^{\circ} \mathrm{C} / 5 \mathrm{~h}$. In both samples CB agglomerates are observed. In the $50 \mathrm{wt} \% \mathrm{CB}$ sample, these agglomerates show a great packaging that allow the formation of conductive paths. However, in the sample with $10 \mathrm{wt} . \% \mathrm{CB}$, the CB agglomerates are isolated in the silica matrix, so the interconnection is very unlikely and the conduction is not favored. Moreover, in this sample, the silica matrix shows microcracks related to differences in the thermal stresses coefficient of thermal expansion between the matrix and the $C B$ agglomerates. As expected, coating with high $\mathrm{CB}$ content allows reaching the conduction percolation limit. Porous of $\sim 500 \mathrm{~nm}$ in equivalent diameter are clearly observed in $\mathrm{SG} \mathrm{CB}-\mathrm{SiO}_{2}$ coating with Triton. The interconnection between $\mathrm{CB}$ agglomerates in coatings having surfactant seem to resemble a foamed type structure originated by the interaction of CB agglomerated for low surfactant additions. The porosity of the coating is not observed in the coating bulk and it is correlated with surface heterogeneities during drying of the coating.

In addition, the resistivity of samples with $50 \mathrm{wt} . \% \mathrm{CB}$, with different surfactant concentrations (Fig. 5b) was measured. It can be seen that resistivity decreases with the Triton $\mathrm{X}-100$ concentration, and remains approximately constant for surfactant addition above $2.75 \mathrm{wt}$. $\%$. Resistivity values as low of $7 \times 10^{-5} \Omega \mathrm{m}$ are obtained. These values are, to our knowledge, the lowest ones reported in sol gel based coatings.

Besides the electrical properties, it is necessary to consider the coating adhesion on the substrates because there must be an equilibrium between good electrical response and appropriated mechanical properties. The samples with high $\mathrm{CB}$ concentration, $60-70 \mathrm{wt} . \%$, present poor adhesion as the $\mathrm{CB}$ nanoparticles/agglomerated detached from the coating. The coatings with lower resistivity values are those with $50 \mathrm{wt} . \%$ $\mathrm{CB}$ and $2.75-5$ wt. \% Triton $\mathrm{X}-100$ since the silica matrix is able to encapsulate the CB. 


\subsection{Mercury intrusion porosimetry}

The Mercury intrusion porosimetry provides a porosity distribution of the dried powder, Fig. 8. Porosity can be consider as defects in the coating even the percolation still exists. The data obtained by this technique can be compared with the microstructural information from FE-SEM. Generally speaking in a pore formed between spherical particles, the porous volume is approximately $1 / 3$ of the particle volume. The powders without surfactant showed a porosity distribution maximum located at $\sim 90 \mathrm{~nm}$, then, the agglomerate size that produces this porosity can be calculated as $\sim 130 \mathrm{~nm}$. The $90 \mathrm{~nm}$ peak could be attributed to pores between agglomerates of CB particles. In samples processed with Triton X-100, an additional broad contribution at $\sim 500 \mathrm{~nm}$ appeared. The broad $500 \mathrm{~nm}$ peak was also formed by similar size CB agglomerates, but the surfactant presence caused a connection between agglomerates that produced a foamed type structured.

\subsection{Raman spectroscopy}

Fig. 9 shows the Raman spectra of SG $\mathrm{CB}-\mathrm{SiO}_{2}$ with 50 wt.\% CB without surfactant at different sintering temperature (Fig. 9a) and with different surfactant concentration thermally treated at $300{ }^{\circ} \mathrm{C} 5 \mathrm{~h}$ (Fig. 9b). In both graphs, we observe two Raman peaks belonging to $\mathrm{CB}$. The first one, $\sim 1357 \mathrm{~cm}^{-1}$, corresponds to a disorder state of carbon (D), specifically to $s p^{3}$-bonded (tetrahedral) carbons, and the second one, $\sim 1590 \mathrm{~cm}^{-1}$, corresponds to the graphitic carbon (ordered state, $G$ ), $s p^{2}$-bonded (trigonal) carbons, where the $\mathrm{C}-\mathrm{C}$ bonds vibrate in the graphitic plane [39-43]. The amorphous carbon is due to bond dislocations. The position, half width and intensity of the Raman peaks depend on the graphitization index of $\mathrm{C}$ in the oxycarbide structure, the crystal size and the defects on the microstructure of carbon coating [44,45].

Fig. 9a shows a relevant blue shift of the Raman crystalline mode $(G)\left(\sim 12 \mathrm{~cm}^{-1}\right)$ when the sintering temperature increases. This behavior indicates an increase of the bonding force constant, that is, the covalent $\mathrm{C}-\mathrm{C}$ bond in the graphitic plane increases in strength. This could be associated to the matrix densification with the thermal treatment that creates a compression effect on the CB nanoparticles. In addition, increasing the temperature of the thermal treatment enhanced the interaction between silica matrix and CB nanoparticles, with the appearance of $\mathrm{Si}-\mathrm{C}$ and $\mathrm{Si}-\mathrm{O}-\mathrm{C}$ bonds that could effectively contribute to the compression effect. However, it is necessary to remark that the blue shift is only observed in the ordered G Raman mode but not in the disordered D Raman mode. A crystalline structure is more favorable to be compressed than an amorphous one because the existence of different bond distances and angles and structural defects, allow the absorption of the compression forces. The broadening of the Raman mode $\mathrm{D}$ and the low bonding force constant of this peak, account for this effect. Moderate annealing of amorphous carbon films has been used to modify the ordered state $G$, independently of the D mode [46].

Fig. $9 \mathrm{~b}$ shows the Raman spectra of samples with $50 \mathrm{wt} \%$ $\mathrm{CB}$, treated at the same temperature $\left(300^{\circ} \mathrm{C} / 5 \mathrm{~h}\right)$ with different concentrations of surfactant. It is also observed a relevant shift $\left(11 \mathrm{~cm}^{-1}\right)$ in the ordered state peak for sample with 5 wt. $\%$ Triton X-100, and a small shift $\left(3.6 \mathrm{~cm}^{-1}\right)$ for sample with 2.75 wt.\%. The Triton X-100 addition results in greater homogeneity in the coating, due to a better dispersion and encapsulation of CB particles in the matrix. Therefore, a higher concentration of surfactant produces better interconnection between nanoparticles, giving place to a more homogeneous lattice stress distribution that contributes to CB nanoparticles compression during the densification, and also results in a Raman blue shift. These results are consistent with those obtained in mercury intrusion porosimetry, and reinforced the explanation of the dependence of resistivity with CB microstructural parameters.

Intensity of $G$ peak $\left(I_{G}\right)$ strongly depends on polarizability of $\pi$ states in the $\mathrm{sp}^{2}$-bonded of carbon and intensity of $D$ peak $\left(I_{D}\right)$ raises with the increase of disorder or with the decrease of crystal sizes in the carbon structure $[43-45,47]$. For amorphous carbon the intensity ratio is $\mathrm{I}_{\mathrm{D}} / \mathrm{I}_{\mathrm{G}} \approx 1$. In addition, it can decrease, $I_{D} / I_{G}<1$, when the defects are reduced or carbon atoms are ordered. When the ratio increases, $I_{D} / I_{G}>1$, the carbon structure is nanoporous. In our case, the intensity ratio of Raman spectra was $I_{D} / I_{G} \approx 1$, so the carbon coatings were mainly amorphous. However, in Fig. 9a it can be observed a slight change in the $I_{G}$ that decreases respect to $I_{D}$ with the sintering temperature, so there is a tendency to reach a ratio $I_{D} / I_{G}>1$. This tendency can also be observed as the surfactant concentration increases, Fig. $9 \mathrm{~b}$.

Depth profile Raman image having high spectral and spatial Raman resolution of the coating is obtained based on the
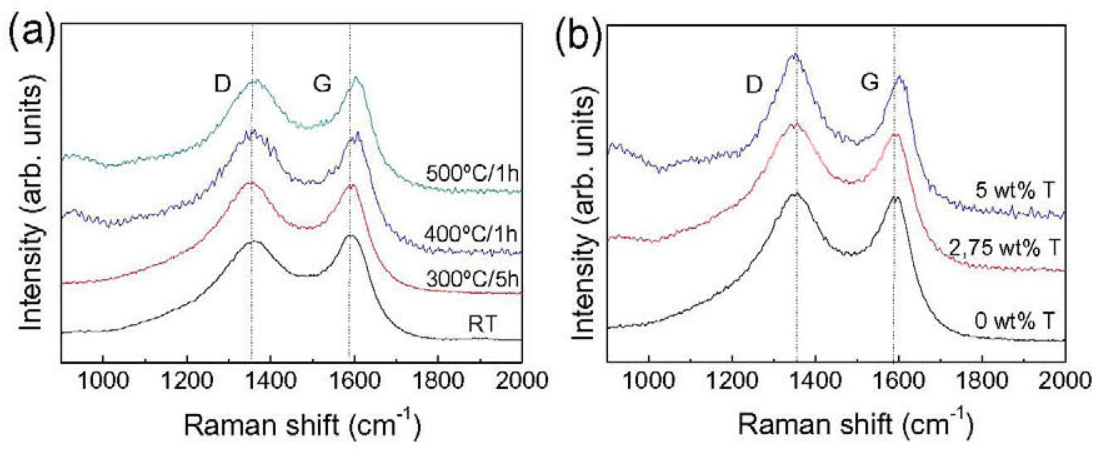

Fig. 9 - Raman spectra of SG CB-SiO ${ }_{2}$ with 50 wt.\% CB: (a) without surfactant at different sintering temperature and (b) with different surfactant concentration thermally treated at $300^{\circ} \mathrm{C} 5 \mathrm{~h}$. 

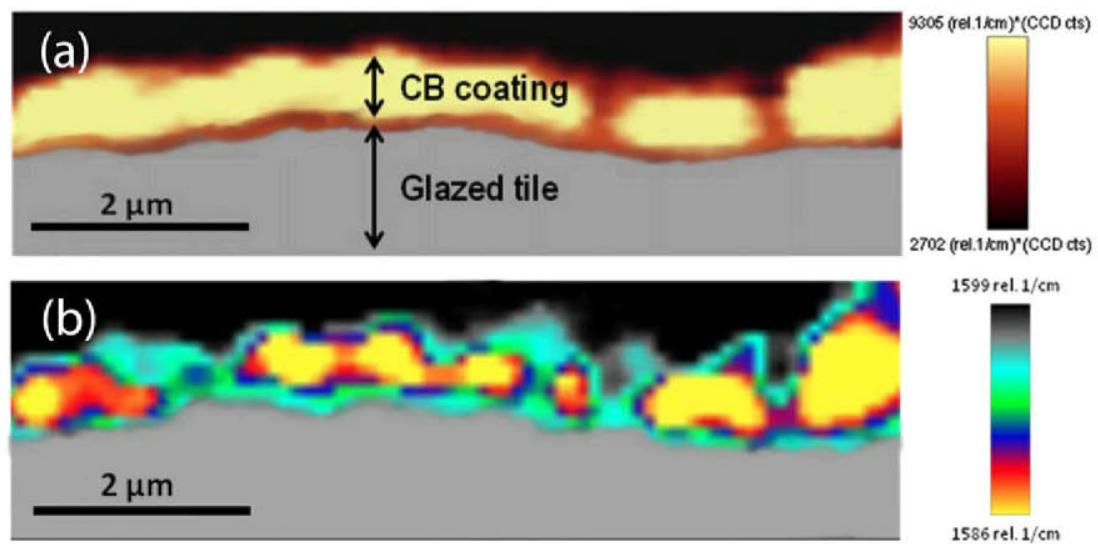

Fig. 10 - High resolution depth profile Raman images: (a) G Raman intensity and (b) G Raman shift of the SG CB-SiO ${ }_{2}$ with $50 \mathrm{wt} . \% \mathrm{CB}$, thermally treated at $300^{\circ} \mathrm{C} 5 \mathrm{~h}$.

optical resolution diffraction of the confocal microscope and the piezo-driven scan platform 3D displacements in steps of $50 \mathrm{~nm}$. Fig. 10a shows the CB Raman signal where the brightest areas correspond to the highest $C B$ Raman intensity. According to the image the coating thickness is $\sim 600 \mathrm{~nm}$ that it is in good agreement with the previous one obtained by FESEM. The depth profile of the G Raman peak is shown in Fig. 10b. The green-blue areas show a blue shift due to a higher lattice compression. This effect occurs in both the surface of the coating and the interface with the substrate. The CB agglomerates were the solid phase meanwhile the silica solgel was a viscous liquid upon coating deposition. During the drying of the coating the solvent removed silica surrounded the CB agglomerates due to the existence of capillary forces. Thus, the CB agglomerates were compressed by the silica matrix. The $G$ peak Raman shift gradient could be associated to the interface with the silica matrix and thereof the presence of $\mathrm{Si}-\mathrm{C}$ or $\mathrm{Si}-\mathrm{O}-\mathrm{C}$ bonds. However, heating effects owing to the laser power could not be discarded in the centre of the agglomerates where the highest intensity of Raman signal was observed [47]. Heating effects produced Raman red shift. The laser spot should heat homogeneously the coating and, as explained, the laser power was selected to avoid thermal runaway. Then, the existence of different heating zones means that there are structural differences inside the SG $\mathrm{CB}-\mathrm{SiO}_{2}$ coating. The $\mathrm{G}$ peak Raman red shift evidences the presence of carbon agglomerates at the coating interior with a reduced presence of silica that causes a worse densification and protection of this zone. Therefore, this Raman image gives a qualitative idea of the structure inside the submicronic coating. Meanwhile, the coating showed better densification at the surface and higher $\mathrm{CB}$ content was presented at the coating interior.

\section{Conclusions}

We have successfully obtained submicronic conductive composite coatings by the sol-gel technique. The coatings preserve the carbon black (CB) properties and are characterized by their low resistivity and high mechanical adhesion to the substrate. In concordance with the structural and electrical characterization the best composition for these conductive SG CB-SiO ${ }_{2}$ composites is obtained with $50 \mathrm{wt}$ \% $\mathrm{CB}, 5 \mathrm{wt} . \%$ surfactant Triton X-100, and thermally treated at low temperatures, $300-400^{\circ} \mathrm{C}$. The inorganic dielectric silica matrix allows a homogeneous and efficient encapsulation of $\mathrm{CB}$ nanoparticles, avoiding their thermal degradation during the thermal treatment for the densification of the coating. The percolated CB particles provide the electrical character to the coating. To our best knowledge, it is the first time that highly conductive sol gel CB-silica composite coatings have been obtained. The resistivity is as low as $\sim 7 \times 10^{-5} \Omega \mathrm{m}$. These results are very interesting for applications in electronic circuits, such as electrodes, and in dissipation of electrostatic charge.

\section{Acknowledgments}

This work was supported by the Spanish Ministry of Science and Innovation through the Project MAT2010-C21088-C03. The authors acknowledge MA García for critical reading of the manuscript, A del Campo for his help with the Micro Raman spectroscopy and Roca Sanitarios S.A. for the substrates provided.

\section{REFERENCES}

[1] Sun J, Gerberich WW, Lorraine F. Transparent, conductive polymer blend coatings from latex-based dispersions. Prog Org Coat 2007;59:115-21.

[2] Zarras P, Anderson N, Webber C, Irvin DJ, Irvin JA, Guenthner A, et al. Progress in using conductive polymers as corrosioninhibiting coatings. Radiat Phys Chem 2003;68:387-94.

[3] Zhang W, Blackburn RS, Dehghani-Sanij AA. Effect of carbon black concentration on electrical conductivity. J Mater Sci 2007;42:7861-5.

[4] Sharif ShM, Golestani-Fard M, Khatibi E, Sarpoolaky H. Dispersion and stability of carbon black nanoparticles, studied by ultraviolet-visible spectroscopy. J Taiwan Inst Chem Eng 2009;40:524-7.

[5] Aoki Y. Rheological characterization of carbon black/varnish suspensions. Colloids Surf A: Physicochem Eng Aspects 2007;308:79-86. 
[6] Barrie CL, Griffiths PC, Abbott RJ, Grillo I, Kudryashov E, Smyth C. Rheology of aqueous carbon black dispersions. J Colloid Interface Sci 2004;272:210-7.

[7] Arshak K, Moore E, Cavanagh L, Harris J, McConigly B, Cunniffe C, et al. Determination of the electrical behaviour of surfactant treated polymer/carbon black composite gas sensors. Compos Part A 2005;36:487-91.

[8] Zhang X, Cui Y, Lv Z, Li M, Ma S, Cui Z, et al. Carbon nanotubes, conductive carbon black and graphite powder based paste electrodes. Int J Electrochem Sci 2011;6:6063-73.

[9] Richner R, Müller S, Wokaun A. Grafted and crosslinked carbon black as an electrode material for double layer capacitors. Carbon 2002;40:307-14.

[10] Jeffrey Brinker C, George W. Scherer. Sol-gel science: the physics and chemistry of sol-gel processing. California (USA): Elsevier Science; 1989.

[11] Leong CK, Chung DDL. Carbon black dispersions and carbonsilver combinations as thermal pastes that surpass commercial silver and ceramic pastes in providing high thermal contact conductance. Carbon 2004;42:2323-7.

[12] Porcher W, Lestriez B, Jouanneau S, Guyomard D. Optimizing the surfactant for the aqueous processing of LiFePO4 composite electrodes. J Power Sources 2010;195:2835-43.

[13] Leong CK, Chung DDL. Carbon black dispersions as thermal pastes that surpass solder in providing high thermal contact conductance. Carbon 2003;41:2459-69.

[14] Sun J, Gao L. Development of a dispersion process for carbon nanotubes in ceramic matrix by heterocoagulation. Carbon 2003;41:1063-8.

[15] Ha SY, Kim S. Preparation and characterization of sol-gel derived carbon composite ceramic electrodes: electrochemical and XANES study of nitrite reduction. J Electroanal Chem 1999;468:131-8.

[16] Zhang W, Blackburna RS, Dehghani-Sanij A. Electrical conductivity of epoxy resin-carbon black-silica nanocomposites: effect of silica concentration and analysis of polymer curing reaction by FTIR. Script Mater 2007;57:949-52.

[17] Predoi D, Crisan O, Jitianu A, Valsangiacom MC, Raileanu M, Crisan $\mathrm{M}$, et al. Iron oxide in a silica matrix prepared by the sol-gel method. Thin Solid Films 2007;515:6319-23.

[18] Pamidi PVA, Parrado C, Kane SA, Wang J, Smyth MR, Pingarrón J. Sol-gel carbon composite electrode as an amperometric detector for liquid chromatography. Talanta 1997;44:1929-34.

[19] Tan SN, Hua L. Amperometric detection of cytochrome $\mathrm{c}$ by capillary electrophoresis at a sol-gel carbon composite electrode. Anal Chim Acta 2001;450:263-7.

[20] Berguiga L, Bellessa J, Vocanson F, Bernstein E, Plenet JC. Carbon nanotube silica glass composites in thin films by the sol-gel technique. Opt Mat 2006;28:167-71.

[21] Carbajal L, Rubio-Marcos F, Bengochea MA, Fernández JF. Properties related phase evolution in porcelain ceramics. J European Ceramic Soc 2007;27:4065-9.

[22] Won YY, Meeker SP, Trappe V, Weitz DA. Effect of temperature on carbon-black agglomeration in hydrocarbon liquid with adsorbed dispersant. Langmuir 2005;21:924-32.

[23] Ishii C, Koseki K, Amari T, Hanzawa Y, Yoshizawa N, Hatori H, et al. Flow behavior of graphitized carbon black suspensions. Letters to the Editor. Carbon 2001;39:2369-86.

[24] Amari T. Non-linear viscoelastic properties of concentrated suspensions. Prog Org Coat 1997;31:11-9.

[25] Hwang Y, Lee JK, Lee J, Jeong YM, Cheong S, Ahn YC, et al. Production and dispersion stability of nanoparticles in nanofluids. Powder Tech 2008;186:145-53.

[26] González-García CM, González-Martín ML, Gómez-Serrano V, Bruque JM, Labajos-Broncano L. Determination of the free energy of adsorption on carbon blacks of a nonionic surfactant from aqueous solutions. Langmuir 2000;16:3950-6.
[27] Rodrigo Moreno Botella. "Reología de Suspensiones Cerámicas". Consejo Superior de Investigaciones Científicas. Madrid: Bouncopy S.A. 2005, 27-72.

[28] Pakizeh M, Omidkhah MR, Zarringhalam A. Synthesis and characterization of new silica membranes using templatesol-gel technology. Int J Hydrogen Energy 2007;32:1825-36.

[29] Asomoza M, Domínguez MP, Solís S, Lara VH, Bosch P, López T. Hydrolysis catalyst effect on sol - gel silica structure. Mater Lett 1998;36:249-53.

[30] Yoshino H, Kamiya K, Nasu H. IR study on the structural evolution of sol-gel derived $\mathrm{SiO}_{2}$ gels in the early stage of conversion to glasses. J Non-Cryst Solids 1990;126:68-78.

[31] Luna-López JA, Carrillo-López J. FTIR and photoluminescence of annealed silicon rich oxide films. J Superficies y Vacío 2009;22(1):11-4.

[32] Kim YH, Hwang MS, Kima HJ, Kim $J$, Lee Y. Infrared spectroscopy study of low-dielectric-constant fluorineincorporated and carbon-incorporated silicon oxide films. J Appl Phys 2001;90(7):3367-70.

[33] Pruthtikul R, Liewchirakorn P. Correlation between siloxane bond formation and oxygen transmission rate in TEOS xerogel. J Met Mater Miner 2008;18(2):63-6.

[34] Najafi A, Golestani-Fard F, Rezaie HR, Ehsani N. A study on sol-gel synthesis and characterization of $\mathrm{SiC}$ nano powder. J Sol Gel Sci Technol 2011;59:205-14.

[35] Oh T. Comparison between SiOC Thin films fabricated by using plasma enhance chemical vapor deposition and $\mathrm{SiO}_{2}$ thin films by using Fourier transform infrared spectroscopy. J Korean Physic Soc 2010;56(4):1150-5.

[36] Ştefanescu M, Stoia M, Ştefanescu O, Davidescu C, Vlase G, Sfirloaga P. Symthesis and characterization of poly(vinyl alcohol)/ethylene glycol/silica hybrids. Thermal analysis and FT-IR study. Rev Roum Chim 2010;55(1):17-23.

[37] Kaneko T, Nemoto D, Horiguchi A, Miyakawa N. FTIR analysis of a-SiC:H films grown by plasma enhanced CVD. J Crystal Growth 2005;275:1097-101.

[38] Li JP, Steckl AJ, Golecki I, Reidinger F, Wang L, Ning XJ, et al. Structural characterization of nanometer SiC films grown on Si. Appl Phys Lett 1993;62(24):3135-7.

[39] Téllez L, Tamayo A, Mazo MA, Rubio F, Rubio J. Preparación y caracterización de materiales de oxicarburo de silicio mixtos. Bol Soc Esp Ceram 2010;49(2):105-12.

[40] Schwan J, Ulrich S, Batori V, Ehrhardt H, Silva SRP. Raman spectroscopy on amorphous carbon films. J Appl Phys 1996;80(1):440-7.

[41] Grüber T, Zerda TW, Gerspacher M. Raman studies of heattreated carbon blacks. Carbon 1994;32:1377-82.

[42] Grüber T, Zerda TW, Gerspacher M. Three-dimensional morphology of carbon black aggregates. Carbon 1993;31(7):1209-18.

[43] Jawhari T, Roid A, Casado J. Raman spectroscopy characterization of some commercially available carbon black materials. Carbon 1995;33(11):1561-5.

[44] Wang Y, Serrano S, Santiago-Avilés JJ. Raman characterization of carbon nanofibers prepared using electrospinning. Synth Met 2003;138:423-7.

[45] Zhao GM, Yang YQ Zhang W, Luo X, Zhang RJ, Chen Y. Raman scattering characterization of a carbon coating after lowenergy argon ion bombardment. Phys B 2011;406:3876-84.

[46] Chhowalla M, Ferrari AC, Robertson J, Amaratunga GAJ. Evolution of $s p^{2}$ bonding with deposition temperature in tetrahedal amorphous carbon studied by Raman spectroscopy. Appl Phys Lett 2000;76:1419-21.

[47] Zerda TW, Grüber T. Raman study of kinetics of graphitization of carbon blacks. Rubber Chem Technol 2000;73:284-92. 